\title{
Evaluation of rest energy expenditure in patients with non alcoholic fatty liver disease
}

\author{
Andressa OLIVEIRA ${ }^{1}$, Sabrina Alves FERNANDES ${ }^{1}$, Randhall Bruce CARTERI ${ }^{2,3}$ and Cristiane Valle TOV0 ${ }^{1,4}$
}

Received: 15 July 2020

Accepted: 17 December 2020

\begin{abstract}
Background - Non-alcoholic fatty liver disease (NAFLD) is currently considered a global public health problem, with changes in lifestyle being the effective way to treat the disease. To date, there is no recommended standard of assessment to determine the resting energy expenditure (REE) of patients with NAFLD, so that dietary therapy can be properly guided. Objective - To evaluate the REE of patients with NAFLD through indirect calorimetry and compare with different predictive formulas of REE and with REE by electrical bioimpedance analysis (BIA). Assess body composition through BIA, with NAFLD staging and the presence of comorbidities. Methods - They were evaluated in patients with NAFLD over 18 years of age treated at the Gastroenterology outpatient clinic of a tertiary level hospital in southern Brazil. NAFLD staging was performed using liver biopsy or a non-invasive method. Weight, height and body mass index (BMI) were determined in all patients. The short version of the International Physical Activity Questionnaire was used to assess physical activity. Comorbidities as arterial hypertension, diabetes mellitus and dyslipidemia were evaluated. To estimate energy expenditure at rest, Harris-Benedict, Jeor Mifflin-St, World Health Organization and Schofield formulas were used. BIA was used to assess resting metabolic rate (RMR) and body mass, and to measure RMR, indirect calorimetry was also used. Associations between categorical variables were tested with Pearson's $\chi^{2}$ test and between groups with McNemar's test. The level of significance assumed was $5 \%$. The degree of agreement between the REE measurement methods was assessed using the Blan-Altman test. Results - A total of 67 patients were evaluated, $70.5 \%$ male, with a mean age of 59 years and a mean BMI of $33.08 \mathrm{~kg} / \mathrm{m}^{2} \pm 5.13$. The average RMR per CI was $1,753 \mathrm{kcal} \pm 614.58$. When comparing the RMR estimate by different formulas with indirect calorimetry, only the Jeor Mifflin-St formula showed a statistically significant difference $(P=0.0001)$, with a difference of $+318.49 \mathrm{kcal}$. BIA and Harris Benedict's formula presented values closer to CI, 1,658 and 1,845 kcal respectively. Conclusion - We suggest that the Jeor Mifflin-St formula should not be used to estimate the RMR in patients with NAFLD. In the absence of indirect calorimetry, some alternatives can be used safely in this population, such as BIA and the predictive formulas of Harris Benedict, Schofield and the World Health Organization.
\end{abstract}

Keywords - Indirect calorimetry; steatohepatitis; resting energy expenditure; non-alcoholic fatty liver disease.

\section{INTRODUCTION}

Non-alcoholic fatty liver disease (NAFLD) is characterized by an excess of fat accumulation in more than $5 \%$ of hepatocytes, associated with the lack of secondary factors related to it ${ }^{(1)}$. It is the most common liver disorder in western countries, affecting 17 to $46 \%$ of the adult population. Its prevalence has been rising worldwide, and has also been linked with an increasing prevalence of metabolic syndrome ${ }^{(2)}$. It can affect $90 \%$ of morbidly obese patients eligible for bariatric surgery, $69 \%$ of individuals with type 2 diabetes mellitus (T2DM), $50 \%$ of dyslipidemic patients and $7 \%$ of the lean popula$\operatorname{tion}^{(1)}$. The prevalence of nonalcoholic steatohepatitis (NASH) in obese patients without T2DM is $88 \% 0^{(3)}$. It has been associated with hypercaloric diets, high fat intakes (especially saturated fat), as well as refined carbohydrates, sugary drinks and fructose consumption ${ }^{(1)}$.

It is known that each person has their daily caloric needs so that it is sufficient to maintain body homeostasis ${ }^{(4)}$. These caloric needs depend on numerous factors, such as the rest energetic expenditure (REE), which is directly related to body structure, physical activity and diet. This need can be measured directly or indirectly ${ }^{(5)}$.
Currently, the gold standard for resting energy measurement is indirect calorimetry (IC) $)^{(6-8)}$.

IC is a non-invasive and safe method, measuring REE by gas exchange, and uses the Weir Equation (respiratory coefficient $[R Q]=0.83$ ) to assess the volume of oxygen consumed, the volume of carbon dioxide produced and nitrogen excreted, since each calorie consumed requires a certain amount of oxygen to be converted into energy, which are good predictors of REE changes ${ }^{(9)}$.

So far, there is no standard nutritional assessment recommendation for determining REE in patients with liver disease, especially those with NAFLD. Therefore, it is important to evaluate this specific population from a nutritional point of view, to guide the dietary management, avoiding the progression of commonly seen comorbidities, without compromising body homeostasis regarding both lean and fat masses.

The aim of the present study is to evaluate the REE of NAFLD patients, assessed by different methods, comparing IC with different estimation equations of REE and bioelectrical impedance analysis (BIA), regarding NAFLD staging and the presence of comorbidities. 


\section{METHODS}

A cross-sectional study was prospectively conducted evaluating all patients diagnosed with NAFLD seen at the Outpatient Clinic of Gastroenterology at Santa Casa de Misericordia of Porto Alegre, a tertiary care hospital in Southern Brazil, between June 2017 and November 2018. The inclusion criteria were NAFLD patients older than 18 years old, diagnosed by liver biopsy or by non-invasive methods (abdominal ultrasound or other imaging exam).

Moreover, hepatitis B and C, and HIV infected patients, significant alcohol consumption ( $>20 \mathrm{~g} /$ day for women and $>30 \mathrm{~g} /$ day for men) $)^{(10)}$, other causes of chronic liver disease, secondary causes of NAFLD and patients with hepatocellular carcinoma were excluded from this study.

Liver biopsy was recommended according to the guidelines of the American Association for the Study of Liver Disease $(\text { AASLD })^{(11)}$, which recommends biopsy in NAFLD patients presenting high risk of NASH and advanced fibrosis as part of the care protocol. It was then performed by ultrasound-guided technique using Tru-cut needle, and was analyzed by a professional with expertise in liver pathology. Histopathological analysis used Kleiner et al. criteria ${ }^{(12)}$.

All patients had weight, height, waist circumference and body mass index (BMI) assessed at baseline. Weight and height were measured on a Fillizola Anthropometric PL scale with a barefoot patient without excess clothing. The BMI was calculated using the formula Weight $(\mathrm{kg}) /$ height $(\mathrm{cm})^{2}$ and the classification according to the Food and Agriculture Organization / World Health Organization (WHO) $)^{(13)}$.

Physical activity was assessed using the International Physical Activity Questionnaire short version validated questionnaire ${ }^{(14)}$.

Laboratory tests such as ALT, AST, total cholesterol, HDL and LDL, triglycerides, glucose, ferritin and albumin were also performed at baseline, according to the assistance protocols standardized by the hospital. Normal reference values were: ALT 49 IU/L; AST $34 \mathrm{IU} / \mathrm{L}$; total cholesterol $190 \mathrm{mg} / \mathrm{dL}$; HDL $>40 \mathrm{mg} /$ $\mathrm{dL}$; triglycerides $150 \mathrm{mg} / \mathrm{dL}$; glucose $99 \mathrm{mg} / \mathrm{dL}$; ferritin $322 \mathrm{mg} / \mathrm{dL}$ for men and $291 \mathrm{mg} / \mathrm{dL}$ for women; albumin $3.5-55 \mathrm{~g} / \mathrm{dL}$.

Comorbidities as systemic hypertension, diabetes mellitus and dyslipidemia were evaluated.

NAFLD score, a noninvasive fibrosis score, was calculated using the variables available at the moment of inclusion in the study. NAFLD score uses the following variables: age, BMI, T2DM, aminotransferases, platelets and albumin ${ }^{(15)}$. Liver biopsy was recommended for patients with NAFLD score with intermediate (score between -1.455 and 0.675 ) or elevated probability (cutoff point $>0.675$ ) of advanced liver fibrosis.

To perform the BIA, it was used a Biodynamics device model 450 with capacity for approximately 100 tests with full tetra polar charge, that uses four small electrodes attached to the right hand and wrist, and the right ankle and foot. For standardization, measurements were performed on the right side of the body through a low voltage current that passed through the body, measuring the electrical resistance and reactance. This way, measurements of lean mass, fat mass, REE and total body water were obtained ${ }^{(16)}$.

The IC was measured by the Korr ${ }^{\circledR}$ MetaCheck calorimeter, with the patient fasting for 4 hours and resting for 30 minutes before starting the assessment. The measurement was made under conditions of absolute rest for 10 to 30 minutes, with the patient sitting and using a rigid breathing mask, in a stable moment, and the calculation of energy expenditure based on the consumption of $\mathrm{O}^{2}\left(\mathrm{VO}^{2}\right), \mathrm{CO}^{2}$ production $\left(\mathrm{VCO}^{2}\right)$ and urinary urea nitrogen, using the formula $\mathrm{REE}=\left\{\left[3.9\left(\mathrm{VO}^{2}\right)\right]+\left[1.1\left(\mathrm{VCO}^{2}\right)\right]\right\}$, described by Weir in $1949^{(17,18)}$.

To estimate the REE, the following equations were used: Harris-Benedict ${ }^{(19)}$, Jeor Mifflin-St ${ }^{(20)}$, WHO ${ }^{(21)}$, Schofield ${ }^{(22)}$ and Grande \& Keys ${ }^{(23)}$.

For statistical analysis, data was presented as mean and standard deviation or frequency and percentage. Associations between categorical variables were tested with Pearson $\chi^{2}$ test and amongst groups with McNemar test. To compare continuous variables between groups, Student's $t$-test was used for variables with normal distribution or Mann-Whitney for nonparametric distributions. For intra-group comparisons, it was used, according to their distributions, paired $t$-test or Wilcoxon test.

The predictive equations were compared with IC using the Bland-Altman method, and the Student's $t$-test for paired samples was used to compare each equation with IC; also the Student's $t$-test for independent samples was used to compare the same equation between the groups.

All analysis were stored and processed using the Statistical Package for Social Sciences program (PASW Statistics for Windows, Version 18.0. Chicago: SPSS Inc). A significance level of 5\% was adopted. The study was approved by the local Ethics Committee and all patients signed the Informed Consent Form.

\section{RESULTS}

A total of 78 patients were initially evaluated, $11(14,1 \%)$ of which failed to complete the IC test due to the respiratory discomfort during the study. Hence, 67 patients were considered for final analysis. Amongst them, 46 (68.7\%) were female, with a mean age of 59 years old, hypertension was present in $54(80.6 \%)$, T2DM in $49(73.1 \%)$, dyslipidemia in $44(65.7 \%)$ and $37(55.2 \%)$ were not physically active (TABLE 1 ).

Amongst the 55 patients who underwent liver biopsy, $72.4 \%$ had some degree of fibrosis, and amongst those, 23.5\% had advanced fibrosis or cirrhosis (F3 or F4). Most patients (91.7\%) had hepatocyte ballooning. The mean values of biochemical tests show high values of triglycerides and glucose (TABLE 1).

When stratifying the variables analyzed by sex, it is possible to observe that women have a higher percentage of sedentary lifestyle when compared to men and the same occurs with a greater number of comorbidities, triglyceride levels and greater fat mass and a higher percentage of liver fibrosis grade 4 (TABLE 1).

The mean BMI was $33.08 \mathrm{~kg} / \mathrm{m}^{2}$ and the mean REE obtained by IC was $1.753 \mathrm{kcal}$. The mean fat mass and lean mass measured by BIA were $33.98 \mathrm{~kg}$ and $55.10 \mathrm{~kg}$, respectively (TABLES 1 and 2). When evaluating differences between REE by different equations and IC between males and females a significant difference was found for all comparisons (TABLE 3).

Evaluating agreement between the estimations and IC, there are marked differences when considering all patients or when we separated by sex. Overall, significant differences were observed for the JM equation showed the highest difference overestimating REE, whereas HB also showed a high percentual difference, underestimating REE, albeit $\mathrm{HB}$ was not significantly different from IC. The WHO equation showed lower percentual difference compared to IC, albeit showed significant different values when 
TABLE 1. Characterization of patients.

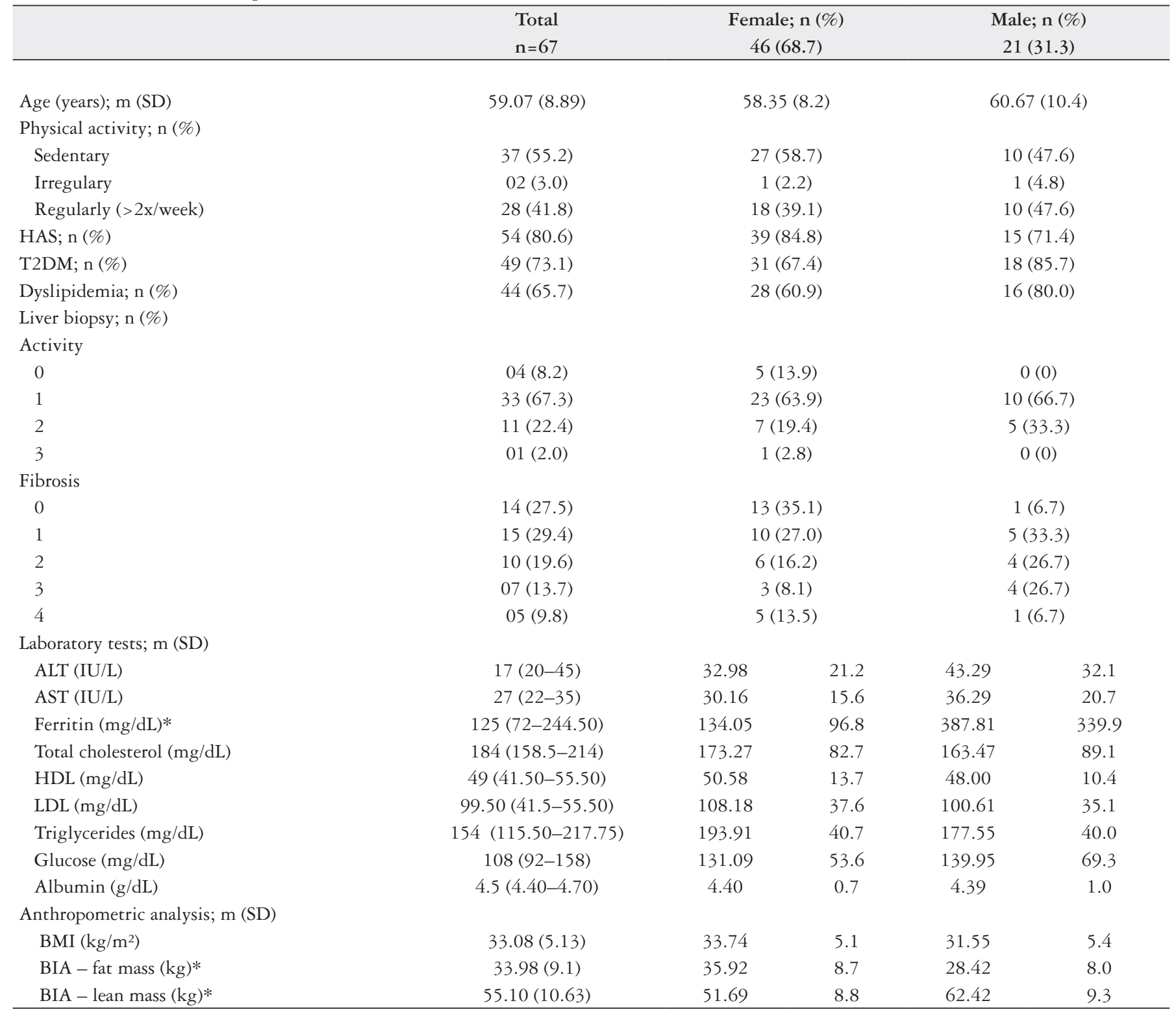

HAS: systemic arterial hypertension; T2DM: type 2 diabetes mellitus; ALT: alanine aminotransferase; AST: aspartate aminotransferase; HDL: high density lipoprotein; LDL: low density lipoprotein; SD: standard deviation; m: mean; 95\%CI: 95\% confidence interval; BIA: bioelectrical impedance analysis; BMI: body mass index. *Signifficant differences (male compared to female; independent samples $t$-test, $P<0.005)$.

TABLE 2. Average values of resting energy expenditure obtained by different methods.

\begin{tabular}{lccccc}
\hline & \multicolumn{2}{c}{ Total $(\mathrm{n}=67)$} & \multicolumn{2}{c}{ Female $(\mathrm{n}=46)$} & \multicolumn{2}{c}{ Male $(\mathrm{n}=21)$} \\
& Mean & SD & Mean & SD & Mean \\
\hline REE IC* & 1753.60 & 614.6 & 1607.48 & 512.0 & 2073.67 \\
REE BIA* & 1658.91 & 304.9 & 1530.85 & 210.4 & 1939.43 \\
REE HB* & 1845.55 & 262.2 & 1723.58 & 139.2 & 2112.73 \\
REE JM* & 1435.11 & 232.9 & 1342.96 & 177.4 & 1636.95 \\
REE WHO* & 1587.55 & 222.4 & 1500.34 & 141.8 & 294.8 \\
REE SC* & 1603.59 & 217.2 & 1513.74 & 111.6 & 214.1 \\
\hline
\end{tabular}

IC: indirect calorimetry; BIA: body composition by bioimpedance; HB: Harris Benedict; JM: Jeor Mifflin- St; WHO: World Health Organization; SC: Schofield; SD: standard deviation. *REE: resting energy expenditure. 
TABLE 3. Comparison between estimation formulas and confidence interval in the assessment of resting energy expenditure.

\begin{tabular}{lcccc}
\hline & Upper limit & Lower limit & \% difference & $\boldsymbol{P}$ value \\
\hline Total (n=67) & & & & \\
REE BIA & 65.4 & -64.3 & 0.6 & 0.132 \\
REE HB & 56.6 & -77.4 & -10.4 & 0.165 \\
REE JM & 80.9 & -52.3 & 14.3 & $0.0001^{*}$ \\
REE WHO & 70.3 & -61.9 & 4.2 & $0.011^{*}$ \\
REE SC & 71.4 & -65.1 & 3.2 & $0.026^{*}$ \\
Female (n=46) & & & & \\
REE BIA & 62.7 & -62.1 & 0.3 & 0.271 \\
REE HB & 52.5 & -75.9 & -11.7 & 0.11 \\
REE JM & 76.8 & -50.9 & 13 & $0.0001^{*}$ \\
REE WHO & 66.3 & -62.7 & 1.8 & 0.139 \\
REE SC & 66.6 & -64.9 & 0.8 & 0.2 \\
Male (n=21) & & & & \\
REE BIA & 72.7 & -70.4 & 1.2 & 0.318 \\
REE HB & 66.7 & -81.4 & -7.3 & 0.785 \\
REE JM & 90.8 & -56.4 & 17.2 & $0.005^{*}$ \\
REE WHO & 79.3 & -60.6 & 9.3 & $0.033^{*}$ \\
REE SC & 82.4 & -65.9 & 8.3 & 0.059 \\
\hline REE & & & &
\end{tabular}

REE: resting energy expenditure; BIA: body composition by bioimpedance; HB: Harris Benedict; JM: Jeor Mifflin-St; WHO: World Health Organization; SC: Schofield. *Anova $(P<0.001)$ - test Sidak post-hoc.

evaluating all patients (TABLE 3). On the other hand, when Bland-Altman concordance analysis was performed, we can see in the graphs in FIGURE 1 that there is $95 \%$ agreement of all methods with IC.

When comparing the estimated REE by different equations with IC, only the BIA and HB equations showed no significant differences with a difference of 94.68 and $-91.95 \mathrm{kcal}$, respectively. (TABLE 4).

The comparative analysis of REE with anthropometric parameters found a positive correlation, showing that the higher the BMI, waist circumference and lean mass, the higher the daily REE. Furthermore, there was also a positive correlation between inflammatory activity and the presence of fibrosis evaluated by liver biopsy (TABLE 5).

When correlating the REE with the presence of comorbidities (systemic arterial hypertension, T2DM and dyslipidemia), no significant difference was found.

\section{DISCUSSION}

The present study evaluated the REE using IC in NAFLD patients. When comparing the estimated REE obtained through different equations with the IC, only the JM equation showed a statistically significant difference $(P<0.01)$. The other equations did not present statistically significant difference when compared to the values obtained by IC. Furthermore, those with inflammatory activity or liver fibrosis, as well as those with high abdominal circumference, high BMI and higher lean mass values, had a higher $\operatorname{REE}(P<0.05)$.

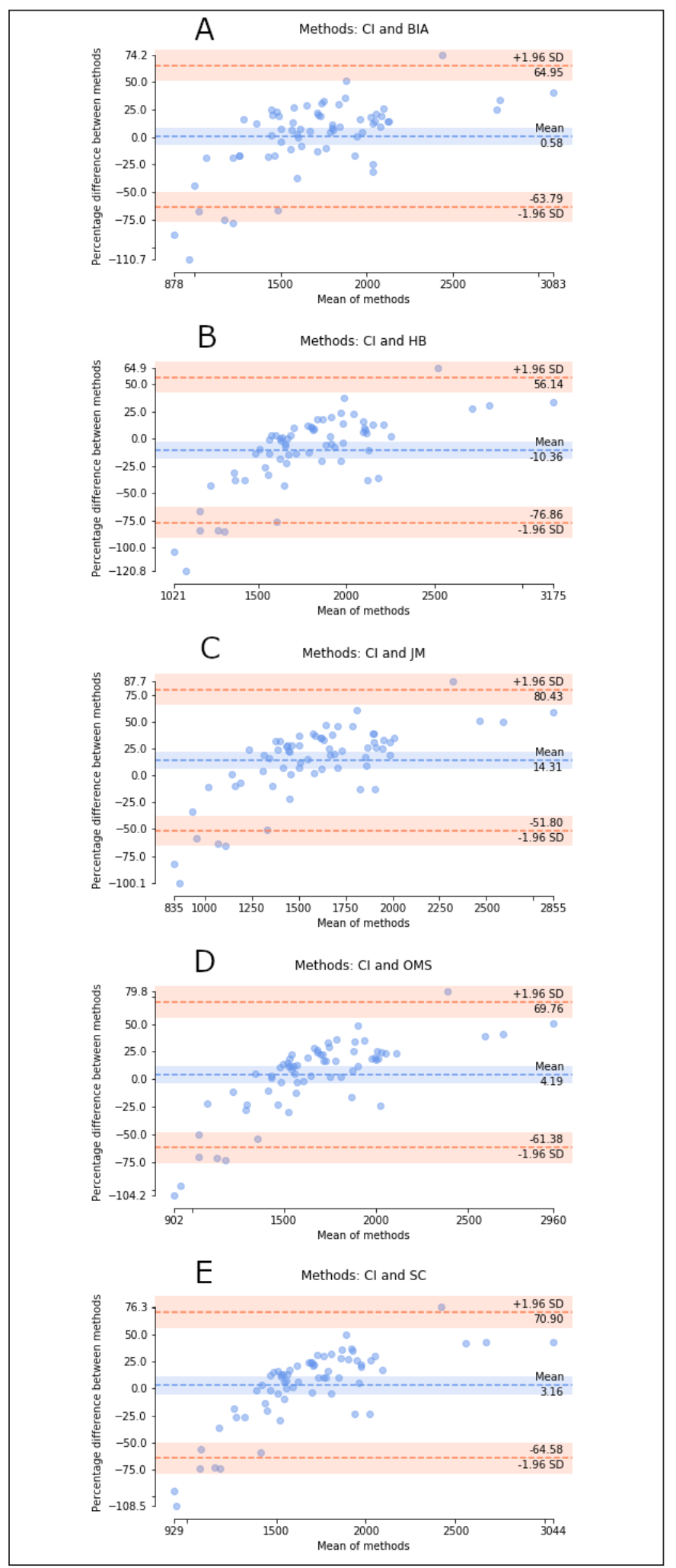

FIGURE 1. Bland-Altman plot for comparisons between IC and predictive methods.

IC: indirect calorimetry; BIA: bioelectrical impedance analysis; HB: Harris Benedict; JM: Jeor Mifflin- St; WHO: World Health Organization; SC: Schofield; SD: standard deviation. 
TABLE 4. Comparison between estimation formulas and IC in the assessment of resting energy expenditure.

\begin{tabular}{lcc}
\hline & Mean difference & $\boldsymbol{P}$ \\
\hline IC x BIA & 94.68 & 0.880 \\
IC x HB & -91.95 & 0.933 \\
IC x JM & 318.49 & $0.0001^{*}$ \\
IC x WHO & 166.04 & 0.157 \\
IC x SC & 150.00 & 0.322 \\
\hline
\end{tabular}

BIA: bioelectrical impedance analysis; HB: Harris Benedict; JM: Jeor Mifflin- St; WHO World Health Organization; SC: Schofield; IC: indirect calorimetry. *Anova $(P<0.001)$ - test Sidak post-hoc

TABLE 5. Correlation between CI energy expenditure and hepatic anthropometric and histopathological parameters.

\begin{tabular}{|c|c|c|}
\hline & Correlation coeficiente & $P$-value \\
\hline $\mathrm{BMI}^{1}$ & 0.252 & 0.035 \\
\hline $\mathrm{CA}^{1}$ & 0.255 & 0.033 \\
\hline $\mathrm{BIA}$ - fat mass ${ }^{1}$ & 0.098 & 0.429 \\
\hline BIA - lean mass ${ }^{1}$ & 0.505 & 0.0001 \\
\hline $\begin{array}{l}\text { Inflammatory } \\
\text { activity }^{2}\end{array}$ & 0.320 & 0.025 \\
\hline Fibrosis $^{2}$ & 0.403 & 0.003 \\
\hline Ballooning $^{2}$ & 0.076 & 0.607 \\
\hline Steatosis $^{2}$ & 0.159 & 0.270 \\
\hline
\end{tabular}

${ }^{1}$ Pearson test. ${ }^{2}$ Spearman's correlation. BIA: body composition by bioimpedance; IMC: body mass index; CA: abdominal circumference.

These findings are different from those observed by Kakisaka et al. ${ }^{(24)}$, which is, to our knowledge, the only study published to date. These authors evaluated the REE using IC in patients with NAFLD, with a mean BMI of $28.3 \mathrm{~kg} / \mathrm{m}^{2}$ and a REE of $1.387 \mathrm{kcal}$, both lower than the results obtained in the present study. These discrepant findings may be due to the difference of the bodies' composition of patients in the present study.

REE has been evaluated in different populations. A previous study compared the REE obtained through IC with predictive equations in 132 young adults without NAFLD. When categorizing the sample according to BMI and gender, higher values of REE were observed in obese men, with a REE average of $1.870 \mathrm{kcal}$, which leads to conclude that in the absence of IC, the choice of the predictive equation will depend on gender and BMI range ${ }^{(25)}$.

When analyzing the REE of 34 patients with pulmonary hypertension, Zanella et al., observed that in that population all predictive equations (Harris Benedict, Food and Agriculture Organization / World Health Organization, Institute of Medicine, Cunningham, Katch-McArdle, and Mifflin- St Jeor) underestimated the REE by $255 \mathrm{kcal}$, and only Cunningham's equation had a lowest difference when compared to $\mathrm{IC}^{(6)}$.

A reliable estimation of REE helps in clinical nutritional management. The current European guideline suggests a $7-10 \%$ weight reduction to improve steatosis, inflammation and liver enzyme levels. Moreover, a reduction higher than 10\% might improve liver fibrosis. These nutritional recommendations associated with increased physical activity are, so far, considered the first-line treatment ${ }^{(26)}$.

In the present study, amongst the measurement methods, there was a variation of -290.93 to $+514.54 \mathrm{kcal}$ when compared to the IC, demonstrating that depending on the method that is chosen, the REE can be under or overestimated, contributing to excessive weight gain. BIA and $\mathrm{HB}$ equation presented values closer to IC. Data regarding the $\mathrm{HB}$ equation corroborated with the findings of Belarmino et al., who conducted a Brazilian study with 126 eutrophic cirrhotic patients of various etiologies (alcohol, viral, cryptogenic and others) with a mean BMI of $21.9 \mathrm{~kg} / \mathrm{m}^{2}$ followed for 16 months. The REE was evaluated through IC and predictive equations, finding a difference of $-31 \mathrm{kcal}$ between the IC and the $\mathrm{HB}$ equation. It was also observed that those with REE above $1.190 \mathrm{kcal}$ had a higher survival rate compared to those with REE below this value ${ }^{(8)}$.

REE may vary according to the disease and the patient's clinical condition, such as obesity, T2DM, trauma, cirrhosis, renal failure, cancer, burns or sepsis. Amongst cirrhotic patients, hypermetabolism may occur in 5 to $34 \%$ of patients. In the obese population, there may be hypometabolism and thermogenic adaptation, an adaptative mechanism that occurs after energy restriction. Altogether, it would allow the conservation of negative energy balance for a longer period of time by decreasing global cellular metabolic activity in order to preserve energy. This way, it would negatively affect weight reduction, leading to a subsequent weight gain ${ }^{(27)}$. Such abnormality was not found in our patients, and can be explained by the presence of greater muscle mass, since fat mass is most of the time considered as a metabolically inactive tissue, contributing less to an increase in REE than lean mass, which is more metabolically active ${ }^{(27)}$.

The mean REE of the population evaluated in our study may be higher compared to the study by Kakisaka et al. ${ }^{(28)}$, where they also evaluated NAFLD patients. This can be due to the higher degree of inflammation and metabolic burden. Another factor that explains the high REE in NAFLD is the presence of T2DM, since carbohydrate oxidation in diabetics is limited by insulin deficiency or insulin resistance. In this way, the oxidation process is shifted towards lipids and proteins. Furthermore, increased hepatic gluconeogenesis is a major contributor to fasting hyperglycemia, which also consumes more energy ${ }^{(27)}$. In the present study, there were a substantial number of patients with T2DM (73.1\%), which could partially justify the higher REE value observed.

As a potential limitation of the present study, we might point that $11(16.4 \%)$ patients were not able to finish the IC test due to respiratory discomfort during its performance. However, losses of up to $20 \%$ are considered acceptable.

In conclusion, we suggest that the Jeor Mifflin-St equation should not be recommended to estimate REE in patients with NAFLD, even showing agreement by the statistical test. In the absence of IC, some alternative tools, such as BIA and Harris Benedict, predictive equations from Schofield and WHO, can be used safely by these patients. Knowledge about individual body composition, as well as the degree of fibrosis, will guide the management of hypo or hypermetabolism in patients with NAFLD. Given the lack of evidence about resting metabolic rate in NAFLD, further studies are needed to better understand energy metabolism at different stages of the disease. 


\section{Authors' contribution}

Oliveira A: research execution, data collection, drafting and final review. Fernandes SA: conception, research execution, drafting and final review. Carteri RB: data analysis, drafting and final review. Tovo CV: conception, research execution, drafting and final review.

\section{Orcid}

Andressa Oliveira: 0000-0001-9828-3165.

Sabrina Fernandes: 0000-0001-8504-603X.

Randhall Bruce Carteri: 0000-0003-4124-9470.

Cristiane Valle Tovo: 0000-0002-7932-5937.

Oliveira A, Fernandes SA, Carteri RB, Tovo CV. Avaliação do gasto energético de repouso em pacientes com doença hepática gordurosa não alcoólica.

Arq Gastroenterol. 2021;58(2):157-63.

RESUMO - Contexto - A doença hepática gordurosa não alcoólica (DHGNA) é considerada, atualmente, um problema de saúde pública global, sendo a mudança no estilo de vida a forma efetiva de tratar a doença. Até o momento não há um padrão de avaliação recomendado para determinar o gasto energético de repouso (GER) de pacientes com DHGNA, para que se possa nortear adequadamente a conduta dietoterápica. Objetivo - Avaliar o GER de pacientes com DHGNA através da calorimetria indireta (CI) e comparar com diferentes fórmulas preditivas do GER e com GER através da bioimpedância elétrica (BIA). Avaliar a composição corporal através da BIA, com o estadiamento da DHGNA e com a presença de comorbidades. Métodos - Foram avaliados em pacientes com DHGNA maiores de 18 anos de idade atendidos no ambulatório de Gastroenterologia de um Hospital de nível terciário do Sul do Brasil. O estadiamento da DHGNA foi realizado através de biópsia hepática ou método não invasivo. Peso, altura e índice de massa corporal (IMC) foram determinados em todos os pacientes. Para avaliação da atividade física foi utilizada a versão curta do International Physical Activity Questionnaire. Foram avaliadas as comorbidades hipertensão arterial, diabetes mellitus e dislipidemia. Para a estimativa do gasto energético de repouso utilizou-se as fórmulas de Harris-Benedict, de Jeor Mifflin-St, da Organização Mundial de Saúde e de Schofield. A BIA foi utilizada para avaliação do GER e da massa corporal, e para aferição do GER também se utilizou a CI. Associações entre variáveis categóricas foram testadas com teste $\chi^{2}$ de Pearson e entre grupos com teste de McNemar. O nível de significância assumido foi de $5 \%$. O grau de concordância entre os métodos de mensuração do GER foi aferido pelo teste de Blan-Altman. Resultados - Foram avaliados 67 pacientes, sendo 70,5\% do sexo masculino, com média de idade de 59 anos e média de IMC $33,08 \mathrm{~kg} / \mathrm{m}^{2} \pm 5,13$. O GER médio por CI foi de $1.753 \mathrm{kcal} \pm 614,58$. Ao comparar a estimativa do GER por diferentes fórmulas com a calorimetria indireta, apenas a fórmula de Jeor Mifflin-St apresentou diferença estatisticamente significativa $(P=0,0001)$, com uma diferença de $+318,49$ kcal. A BIA e a fórmula de Harris Benedict apresentaram valores mais próximos à CI, 1.658 e 1.845 kcal respectivamente. Conclusão - Sugerimos que a fórmula de Jeor Mifflin-St não deva ser utilizada para estimativa do GER em pacientes com DHGNA. $\mathrm{Na}$ ausência da CI algumas alternativas podem ser utilizadas com segurança nesta população, como a BIA e as fórmulas preditivas de Harris Benedict, de Schofield e da Organização Mundial de Saúde.

Palavras-chave - Calorimetria indireta; esteatohepatite; gasto energético de repouso; doença hepática gordurosa não alcoólica.

\section{REFERENCES}

1. Easl-Easd-Easo Clinical Practice Guidelines for the management of non-alcoholic fatty liver disease. J Hepatol 2016;64:1388-1402.

2. Zhu J, Hollis-Hansen K, Wan X, Fei S, Pang X, Meng F, et al. Clinical Guidelines of Non-Alcoholic Fatty Liver Disease: A Systematic Review. World J Gastroenterol. 2016;22:8226-33.

3. Tovo CV, Fernandes SA, Buss C, Mattos AA. Sarcopenia and Non-Alcoholic Fatty Liver Disease: Is There a Relationship? A Systematic Review. World J Hepatol. 2017;9:326-32.

4. Frade RE, Viebig RF, Pereira MS, Ruza NB, Valente TR. Uses of equations and methods to estimatethe basal energetic cost and the total energetic cost of adults that practice physical activities: a case study. Rev Bras Nutr Esportiva. 2016;10:43-9.

5. Kamimura MA, Avesani CM, Draibe SA, Cuppari L. Resting energy expenditure in patients with chronic kidney disease. Rev Nutr. 2008;21:75-84.

6. Zanella PB, Avila CC, de Souza CG. Estimating resting energy expenditure by different methods as compared with indirect calorimetry for patients with pulmonary hypertension. Nutr Clin Pract. 2018;33:217-23.

7. Veronese CBB, Guerra LT, Souza Grigolleti S, Vargas J, Pereira da Rosa AR, Pinto Kruel. CD. Basal energy expenditure measured by indirect calorimetry in patients with squamous cell carcinoma of the esophagus. Nutr Hosp. 2013;28:142-7.

8. Belarmino G, Singer P, Gonzalez MC, Machado NM, Cardinelli CS, Barcelos S, et al. Prognostic value of energy expenditure and respiratory quotient measuring in patients with liver cirrhosis. Clin Nutr. 2019;38:1899-1904.

9. Gottschall CBA, Álvares-da-Silva MR, Camargo ACR, Burtett RM, Da Silveira TR. Nutritional assessment of patients with cirrhosis due to the hepatitis $C$ virus: the application of indirect calorimetry. Arq Gastroenterol. 2004:41:220-4.

10. Brunt EM, Janney CG, Bisceglie AM, Neuschwander-Tetri BA, Bacon BR Nonalcoholic steatohepatitis: a proposal for grading and staging the histological lesions. Am J Gastroenterol. 1999;94:2467-74.
11. Chalasani N, Younossi Z, Lavine JE, Diehl AM, Brunt EM, Cusi K, et al. The diagnosis and management of non-alcoholic fatty liver disease: practice Guideline by the American Association for the Study of Liver Diseases, American College of Gastroenterology, and the American Gastroenterological Association. Hepatology. 2012;55:2005-23.

12. Kleiner DE, Brun EMt, Natta MV, Behling C, Contos MJ, Cummings OW, et al. Design and validation of a histological scoring system for nonalcoholic fatty liver disease. Hepatology. 2005;41:1313-21.

13. Food and Agriculture Organization (FAO). World Health Organization (WHO) Energy and protein requiriments. (WHO Technical Report Series 724) 1985 [Internet]. [cited 2019 Oct 12]. Available from: http://www.fao.org/3/aa040e/ aa040e00.htm\#TOC

14. Lee PH, Macfarlane DJ, Lam TH, Stewart SM. Validity of the International Physical Activity Questionnaire Short Form (IPAQ-SF): a systematic review. Int J Behav Nutr Phys Act. 2011;8:115.

15. Pohl A, Behling C, Oliver D, Kilani M, Monson P, Hassanein T. Serum aminotransferase levels and platelet counts as predictors of degree of fibrosis in chronic hepatitis C virus infection. Am J Gastroenterol. 2001;96:3142-6.

16. TBW Importadora. Bioimpedância Biodynamics 450. Manual de Instrução. [Internet]. [cited 2019 Oct 03]. Available from: https://www.tbw.com.br/bioimpedancia-450

17. Weir JB. New methods for calculating metabolic rate with special reference to protein metabolism. J Physiol. 1949;109:1-9.

18. TBW Importadora. Calorímetro MetaCheck. Manual de instrução. [Internet]. [cited 2019 Oct 03]. Available from: https://www.tbw.com.br/metacheck

19. Harris JA, Benedict FG. A Biometric Study of Human Basal Metabolism. Proc Natl Acad Sci. 1918:4:370-3

20. Mifflin MD, St Jeor ST, Hill LA, Scott BJ, Daugherty SA, Koh YO. A new predictive equation for resting energy expenditure in healthy individuals. Am J Clin Nutr. 1990;51:241-7. 
21. World Health Organization. Energy and protein requirements. Report of a joint FAO/WHO/UNO. Expert consultation. World Health Organ Tech Rep Ser. 1985;724:1-206.

22. Schofiel WN. Predicting basal metabolic rate, News standards and review of previous work. Hum Nutr Clin Nutr. 1985;39:5-41.

23. Grande F, Keys A. Body weight, body composition, and calorie status. In R. S. Goodhart and M. E. Shils, eds. Modern nutrition in health and disease. Philadelphia: Lea \& Febiger; 1980, 27.

24. Endo K, Kakisaka K, Oikawa K, Endo R, Takiawa Y. Comparison of Predicted Energy Expenditure in Japanese Patients with Non-Alcoholic Fatty Liver Disease to Establish a Suitable Nutrition Intervention. J Nutr Sci Vitaminol. 2016;62:108-15.
25. Amaro-Gahete FJ, Sanchez-Delgado G, Alcantara J, Martinez-Tellez B, Muñoz-Hernandez V, Merchan-Ramirez E, et al. Congruent Validity of Resting Energy Expenditure Predictive Equations in Young Adults. Nutrients. 2019;11:223-46.

26. Plauth M, Bernal W, Dasarathy S, Merli M, Plank LD, Schutz T, Bischoff SC. ESPEN guideline on clinical nutrition in liver disease. Clin Nutr. 2019;38:485-521.

27. Rattanachaiwong S, Singer P. Indirect calorimetry as point of care testing Clin Nutr. 2019;S0261-5614.

28. Kakisaka K, Endo K, Oikawa K, Endo R, Takikawa. Comparison of predicted energy expenditure in Japanese patients with non-alcoholic fatty liver disease to establish a suitable nutrition intervention. J Nutr Sci Vitaminol. 2016;62:108-15. 